\title{
Errors Caused by Nitrates and Nitrites in the Determination of Arsenic by the Distillation Method, and a Means for Their Prevention
}

\author{
By J. J. T. Graham and C. M. Smith
}

Insecticide and Fungtcide laboratory, Miscellaneous Division, Bureau of Chemistry, Washington, D. C.

\begin{abstract}
It has been found that nitrates and nitrites interfere in the official method of the Association of Official Agricultural Chemists for total arsenic in insecticides, causing low results. This is probably brought about by the formation of nitrosyl chloride, which passes into the distillate, and there slowly oxidizes the trivalent arsenic to the pentavalent form.

This interference can be prevented by the application of the method of Jannasch and Seidel in which hydrazine sulfate and sodium bromide are used as reducing agents. In addition to giving greater accuracy, this method hastens the volatilization of the arsenic, thereby decreasing the time and the amount of hydrochloric acid required.
\end{abstract}

$\mathrm{T}$ HE determination of arsenic by the method of reduction and distillation as arsenic trichloride has been the subject of numerous investigations. An exhaustive review of the literature concerning this problem is given by Roark and MoDonnell in a paper ${ }^{2}$ describing the application of this method to the determination of arsenic in insecticides. After testing many substances, these authors selected cuprous chloride as the most suitable reducing agent. Following their work, the Association of Official Agricultural Chemists adopted this as an "official" method," and it has since been used in the Bureau of Chemistry with generally satisfactory results. However, in the analysis of commercial calcium and lead arsenates it was found that sometimes duplicate determinations did not agree, and that the results were low in comparison with those obtained by the modified Gooch and Browning method. ${ }^{4}$

It was also observed that delay between distillation and titration accentuated the difference. Impurities in the reagents were at first suspected as the cause of the trouble, but after investigation it was proved that the disturbing factor lay in the sample itself.

The decrease in the titrations with the lapse of time indicated oxidation in the distillate and led the writers to suspect the presence of an oxidizing substance in the sample. In order to cause the effect noticed, the interfering substance or substances must either be volatile or produce volatile products which are oxidizers. These conditions, considered in connection with the process of manufacture of calcium and lead arsenates, practically limit the possible oxidizing substances to nitrates and nitrites. Qualitative tests on a sample of calcium arsenate giving discrepant results showed the presence of a considerable amount of nitrate and a trace of nitrite. Subsequent determination of the nitrogen in this sample gave results equivalent to 3.50 per cent of nitrogen pentoxide. In all cases in which trouble was experienced nitrates were found. Working upon this suggestion, experiments were planned to determine more definitely the action of nitrates and nitrites and to devise a modification of the method to overcome this source of error.

\section{StaNDaRd SOLUTIONS}

The following standard solutions were prepared: ARSENIC ACID - A solution was prepared from solid arsenic

\footnotetext{
3 Received October 22, 1921.

2 TuIs JovrNal, 8 (1916), 327.

'Assoc. Official Agr. Chemists' Methods, 2nd edition (1920), 54.

- Dept. of Agrieulture, Chem. Bull. 105 (1907), 166.
}

acid which had been purified by several crystallizations from water. It contained $26.05 \mathrm{~g}$. of arsenic pentoxide per liter, as determined by analysis both by the official distillation method ${ }^{3}$ and by the fooch and Browning method of reduction with potassium iodide and subsequent titration with standard iodine solution.

NITRATE SOLUTIONS-(1) a solution containing $10.0 \mathrm{~g}$. of lead nitrate per liter; (2) a solution containing $4.954 \mathrm{~g}$. of calcium nitrate per liter.

NITRITE SOLUTION-A solution containing $4.167 \mathrm{~g}$. of sodium nitrite per liter (the same concentration of nitrogen as in the standard nitrate solutions).

\section{Experimental Procedure}

The analyses were made on 25-cc. samples of the arsenic pentoxide solution to which were added varying amounts of the nitrate or nitrite solutions. (The weight of calcium arsenate usually taken for analysis is $1.5 \mathrm{~g}$., so that on this basis the amount of nitrate introduced with $25 \mathrm{cc}$. of the standard nitrate solutions is equivalent to about 5.4 per cent of nitrogen pentoxide in a commercial sample.) In the experimental procedure the official method was followed except as noted, and all determinations were made in duplicate. The reducing agents were first introduced into the distillation flasks, then aliquot portions of the arsenic pentoxide and of the nitrate or nitrite solutions were added by means of pipets, followed by $100 \mathrm{cc}$. of concentrated hydrochloric acid. A total of 250 cc. of hydrochloric acid was used in each determination. The distillates were made to 1 liter, and aliquot parts were titrated according to the bromate method of Gyory, ${ }^{5,6}$ as presented to the Association of Official Agricultural Chemists by the referee on insecticides and fungicides at the 1920 meeting. As the proceedings of this meeting have not yet been published, the details of the method will be quoted here:

Transfer 200-cc. aliquots of the distillate to 500-cc. Erlenmeyer flasks, heat to $90^{\circ} \mathrm{C}$., and titrate with the standard potassium bromate solution (1.688 $\mathrm{g}$. potassium bromate to 1 liter of water standardized against arsenious oxide in approximately $2 \mathrm{~N} \mathrm{HCl}$ ), using methyl orange as indicator. The indicator should not be added until near the end of the titration, and the solution should be rotated continuously to avoid any local excess of the titrating solution. The end of the reaction is indicated by a change from red to colorless and is very sharp.

The first experiments showed conclusively that both nitrates and nitrites had a marked effect on the results. When $0.25 \mathrm{~g}$. of lead nitrate was used the distillate in the receiving flask was decidedly yellow and even $0.05 \mathrm{~g}$. caused a slight yellow coloration. Nitrites produced the same effect. This color disappeared when the distillates were made to volume in a liter flask. On heating, the distillate slowly destroyed the color of methyl orange, but the fading was not sufficiently rapid to interfere with the titration. Aliquot portions titrated at successive intervals showed a steady decline in the arsenic value.

\footnotetext{
IZ. anal. Chem., 32 (1893), 415.

- Enough experiments were made to show that the bromate method gave the same results as the iodine titration method, and it was used because of its directness and greater speed.
} 


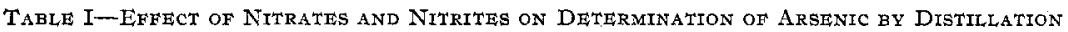
(Arsenic pentoxide taken in each experiment $0.1303 \mathrm{~g}$.)

\begin{tabular}{|c|c|}
\hline \multicolumn{2}{|c|}{-REDUCING AGENTS- } \\
\hline $\begin{array}{l}\text { Chloride } \\
\text { Grams. }\end{array}$ & $\begin{array}{c}\text { Additional } \\
\text { Grams }\end{array}$ \\
\hline 5 & ..... \\
\hline 5 & $\ldots \ldots$ \\
\hline $\begin{array}{r}5 \\
5\end{array}$ & $\cdots \cdots$ \\
\hline 5 & $\ldots \ldots$ \\
\hline $\begin{array}{r}15 \\
5\end{array}$ & $\mathrm{HeSO}+\mathrm{io}^{\circ}$ \\
\hline 5 & $\mathrm{FeSO} 410$ \\
\hline $\begin{array}{l}5 \\
5\end{array}$ & $\begin{array}{l}\mathrm{NaBr} \\
\mathrm{NaBr}\end{array}$ \\
\hline 5 & Aniline oil 1 (cc) \\
\hline 5 & $\begin{array}{l}\text { Aniline oil } 5 \text { (cc.) } \\
\text { Anilitie oil } 5 \text { (cc.) }\end{array}$ \\
\hline $\begin{array}{l}5 \\
5\end{array}$ & $\begin{array}{l}\mathrm{NH}_{4} \mathrm{Cl} 2 \\
\mathrm{NH}_{4} \mathrm{Cl} 2+\mathrm{NaBr} 1\end{array}$ \\
\hline 5 & $\begin{array}{l}\text { Hydrazine sulfate } 2 \\
\text { Hydrazine sulfate } 2\end{array}$ \\
\hline 5 & Hydrazine sulfate 1 \\
\hline 5 & $\begin{array}{l}\text { Hydrazine sulfate } 1 \\
\text { Hydrazine sulfate }\end{array}$ \\
\hline 5 & Hydrazine sulfate 1 \\
\hline 5 & Hydrazine sulfate 1 \\
\hline Hydrazit & Sulfate \\
\hline 4 & ' \\
\hline $\begin{array}{l}2 \\
2\end{array}$ & $\cdots \ldots$ \\
\hline 3 & $\mathrm{NaBr} i$ \\
\hline $\begin{array}{l}2 \\
1 \\
1\end{array}$ & $\begin{array}{l}\mathrm{NaBr} 1 \\
\mathrm{NaBr} 1 \\
\mathrm{NaBr} 1\end{array}$ \\
\hline
\end{tabular}

\begin{tabular}{|c|c|}
\hline $\begin{array}{l}\text { Lead } \\
\text { Nitrate } \\
\text { Taken } \\
\text { Grams }\end{array}$ & $\begin{array}{l}\text { Calcium } \\
\text { Nitrate } \\
\text { Taken } \\
\text { Grams }\end{array}$ \\
\hline $\begin{array}{l}0.05 \\
0.25\end{array}$ & $\ldots$ \\
\hline . & 0.124 \\
\hline $\begin{array}{l}0.25 \\
0.25\end{array}$ & $\begin{array}{l}\cdots \\
\cdots \\
\cdots\end{array}$ \\
\hline $0 . \dot{2} 5$ & 0.124 \\
\hline $\begin{array}{l}0.25 \\
0.25\end{array}$ & $\begin{array}{c}0.124 \\
\ldots \\
\ldots\end{array}$ \\
\hline $\begin{array}{l}0.25 \\
0.25 \\
0.25\end{array}$ & $\begin{array}{l}\cdots \\
\cdots \\
\cdots\end{array}$ \\
\hline$\because$ & 0.124 \\
\hline $\begin{array}{c}0.25 \\
\cdots\end{array}$ & $0 . \dot{1} 24$ \\
\hline 0.25 & $\cdots$ \\
\hline 0.25 & $\cdots$ \\
\hline$\cdots$ & 0.124 \\
\hline $\begin{array}{l}0.25 \\
0.25\end{array}$ & $\cdots$ \\
\hline $0 . \dot{2} 5$ & $\begin{array}{l}0.124 \\
0.12\end{array}$ \\
\hline 0.25 & $\begin{array}{l}0.124 \\
0.124\end{array}$ \\
\hline
\end{tabular}

Sodium
Nitrite
Taken I
Grams di
$\ldots$

\begin{tabular}{|c|c|}
\hline $\begin{array}{l}\text { itrated } \\
\text { mme- }\end{array}$ & $\begin{array}{l}\text { Titrate } \\
\text { after }\end{array}$ \\
\hline & \\
\hline $\begin{array}{l}1303 \\
1303\end{array}$ & \\
\hline $\begin{array}{l}1289 \\
1301\end{array}$ & 0.1270 \\
\hline 1257 & \\
\hline 129 & \\
\hline
\end{tabular}

$\begin{array}{ll}.104 & 0.1257 \\ \cdots & 0.1296\end{array}$

$\cdots \quad 0.1276$

$\begin{array}{ll}\ldots & 0.1303 \\ \ldots & 0.1277\end{array}$

$\begin{array}{lll}\ldots & 0.1277 & 0.1291 \\ \cdots & 0.1303 & 0.1277\end{array}$

... 0.1300

$0.104 \quad 0.134$

$\begin{array}{lll} & 0.1292 & \end{array}$

$0.104 \quad 0.1303$

0.1303 0 i303

$\cdots \quad 0.1303$

$\ldots \quad 0.1303$

... 0.1299

0,1301

... 0.1303

$\cdots$

$\ldots$

0.1303

0.1303

.. $\quad 0.1212$

0.1009
0.0908
0.1303
0.1303

0.1303
0.1303
0.1303

o. $\ddot{0} \dot{0}$

$0.1303 \quad 0.1303$

$\begin{array}{lll}0.1303 & 0.1303 & 0.1303 \\ 0.1303 & 0.1303 \\ 0.1303 & 0.1303 \\ & 0.1303\end{array}$

* The numbers in parent

\section{REDUCING Agents}

Having demonstrated that nitrates and nitrites cause low results, the next step was to find a method of reduction whereby the arsenic could be accurately determined in the presence of these substances. Experiments were made with various reducing agents and combinations thereof, using in every case $25 \mathrm{cc}$. each of the standard arsenic solution and nitrate or nitrite solution. The use of a larger quantity of cuprous chloride was first tried, but even $15 \mathrm{~g}$. of this material made practically no change in the results. Ferrous sulfate in combination with cuprous chloride gave distillates which were decidedly yellow, oxidized methyl orange very rapidly, and showed a more rapid decline in the arsenic value than when cuprous chloride was used alone. Rohmer ${ }^{7}$ noticed that hydrobromic acid accelerated the reducing action of sulfur dioxide, and attributed to it a catalytic effect. This suggested the use of sodium bromide in combination with cuprous chloride. Distillations made in this way, however, showed only a slight improvement over those made with cuprous chloride alone.

Jannasch and Seidel ${ }^{8}$ found that hydrobromic acid together with a salt of hydrazine gave excellent results in the reduction of arsenic. Since hydrazine is such a strong reducing agent it seemed likely that it might destroy the nitrates as well as reduce the arsenic. It was used at first alone and then in combination with cuprous chloride and with sodium bromide. The use of hydrazine sulfate alone eliminated the yellow color and prevented the gradual oxidation of the distillate, but the arsenic was not completely reduced in the time required to obtain $250 \mathrm{cc}$. of distillate (30 to 40 min.), even when as much as $4 \mathrm{~g}$. of hydrazine sulfate were employed. (This is in accord with the results of Jannasch and Seidel, who found that several hours were required to secure complete reduction by hydrazine sulfate alone.) When the distillations were made with $5 \mathrm{~g}$. of cuprous chloride and $1 \mathrm{~g}$. of hydrazine sulfate the arsenic was completely reduced, but the oxidation of the distillate was not elimi-

7 Ber., 34 (1901), 33.

8 Ibid., 43 (1910), 1218; J. prakt. Chem., 91 (1915), 133. nated. When, however, the hydrazine sulfate was increased to $2 \mathrm{~g}$. the oxidation of the distillate was completely prevented. Jannasch and Seidel found that the addition of a bromide to the hydrazine sulfate greatly hastened the reduction of the arsenic, and the writers have found that sodium bromide and hydrazine sulfate when added to the cuprous chloride also completely destroy nitrates. Later experiments showed that equally as good results were obtained without the use of cuprous chloride. One gram of hydrazine sulfate and $1 \mathrm{~g}$, of sodium bromide proved sufficient where the quantity of arsenic pentoxide present did not exceed $0.75 \mathrm{~g}$.

The investigation included some attempts to find a satisfactory substance to destroy the nitrates, which would be cheaper than the hydrazine sulfate. Ammonium chloride and aniline, owing to their known action on nitric acid and nitrites, respectively, were tried but proved to be of no value. The conditions to be fulfilled in this distillation are so circumscribed that the list of possible substances as reducing agents is limited.

\section{RESULTS OF EXPERIMENTS}

The results given in Table I show conclusively that, in the presence of nitrates (or nitrites), the distillation method for arsenic as ordinarily carried out, using cuprous chloride or cuprous chloride and ferrous sulfate as the reducing agents, gives low results. This is due to some volatile substance, possibly nitrosyl chloride, carried over in the distillate that oxidizes the arsenic trioxide. The extent of this oxidation depends largely upon the length of time the distillate stands before titration. Where a number of distillations are being carried on at the same time, it is impossible to titrate all of them immediately and the error caused by this oxidation may be a very material one. This error may be avoided by the use of hydrazine sulfate as the reducing agent, or preferably hydrazine sulfate and sodium bromide, in which case the reduction takes place much more rapidly. The nitrates and nitrites are probably reduced to nitrogen by the hydrazine sulfate. 